\title{
Modeling of two-phase transport in proton exchange membrane electrolyzer cells for hydrogen energy
}

Bo Han ${ }^{1,2}$, Jingke Mo ${ }^{1}$, Zhenye Kang ${ }^{1}$, Gaoqiang Yang ${ }^{1}$, William Barnhill ${ }^{1}$, Feng-Yuan Zhang, ${ }^{1, *}$

\author{
${ }^{1}$ Nanodynamics and High-Efficiency Lab for Propulsion and Power (NanoHELP) \\ Department of Mechanical, Aerospace \& Biomedical Engineering \\ UT Space Institute, University of Tennessee, Knoxville (UTK) \\ Tullahoma, TN 37388, USA
}

${ }^{2}$ Present address: School of Aeronautics and Astronautics

Zhejiang University

Hangzhou, Zhejiang 310027, China

*Corresponding author. Tel: +1-931-393-7428; Email address: fzhang@utk.edu 


\begin{abstract}
Multiphase transport inside a proton exchange membrane electrolyzer cell (PEMEC) plays an important role in its performance and design. Most PEMEC modeling studies so far have mainly focused on its electrochemical performance prediction and analysis, and fundamental understanding of the effect of multiphase transport on the cell performance is still lacking. In this study, a two-phase mathematical model is developed to investigate the transport properties inside liquid/gas diffusion layers (LGDLs) and to explore their effects on the PEMEC voltage and efficiency. Sudden changes in the PEMEC voltage and efficiency are captured for the first time as the current density reaches a limiting value, and the limiting current density is greatly impacted by the LGDL contact angle, porosity, and thickness. In addition, the liquid water distribution and cell performance in PEMECs with different important operating and physical parameters are examined and discussed in detail. Increasing the LGDL porosity or/and decreasing its surface contact angle will improve the PEMEC performance especially at the high current density. The thickness changes of the LGDL and membrane also have significant impacts on the cell voltage and efficiency. The model can effectively examine two-phase transport properties and provide useful information for design optimization of a PEMEC.
\end{abstract}

Keywords: proton exchange membrane electrolyzer cell (PEMEC), liquid saturation, two-phase transport, modeling, performance and efficiency 


\section{Introduction}

Electrolyzer cell technology provides a sustainable solution for renewable energy storage and hydrogen production. Among all types of electrolyzer cell systems, PEMEC is providing a promising solution for hydrogen and oxygen production and receiving more and more attention due to their higher energy efficiency/density, faster charging/discharging, and a more compact design [1-5]. A PEMEC has a similar configuration and operating components to a PEM fuel cell (PEMFC) [6-11]. Figure 1 shows a three-dimensional geometry schematic of a typical single-cell PEMEC, which consists of flow channels, liquid/gas diffusion layers (LGDL), catalyst layers (CL), and the PEM. During operation, liquid water is fed into the flow channel at the anode, transports across the porous LGDL, and is electrochemically split into oxygen and hydrogen at the CL. Because of the complexity of electrode structures and material properties, the liquid water transport in the LGDL is one of the challenging issues in PEMECs and plays an important role in the cell optimization and design. In particular, cell operating parameters and LGDL properties including current density, porosity, contact angle, and thickness have a significant impact on the gas-liquid two-phase transport process and consequently influence the PEMEC performance and efficiency.

In the past years, some efforts have been made in two-phase transport and electrochemical performance modeling of PEMFCs [12-30] and direct methanol fuel cells (DMFCs) [31-36], which will be useful for modeling PEMEC issues. Wang et al [15] first employed a multiphase mixture model to study two-phase transport phenomena at the cathode of a PEMFC. Meng et al. [16] developed a two-phase model for calculating the effects of flooding dynamics and liquid water transport on the PEMFC performance. The liquid saturation distribution in gas diffusion layers (GDL) was simulated at different operating conditions and the effects of interfacial liquid 
saturation between the GDL and gas channel (GC) on the cell performance were investigated. Wang [18] developed a three-dimensional mathematical model to simulate two-phase flow and electrochemical processes in both the anode and cathode GDL of a PEMFC. Wang et al. [31] and Yang et al. [33] also conducted numerical models to simulate two-phase transport mechanisms in a liquid-feed DMFC. Although PEMECs share many issues with fuel cells and some two-phase flow models on PEMFCs and DMFCs are available, many challenges in implementing fuel cell models for PEMECs remain, such as model validation, coupling of twophase flow and performance/efficiency modeling, equivalent resistance modeling, gas bubble dynamics and interfacial effects and so on.

Several efforts have also been made in the two-phase flow and performance analysis of electrolyzer cells [37-44]. Grigoriev et al. [45] reported a two-phase mathematical model for a high pressure PEMEC. In their model, the gas/liquid two-phase transport equations were based on the general mass and momentum conservations of gas and liquid phases across the LGDL and the Leverett function was used to calculate the liquid saturation in a hydrophilic LGDL. The interfacial saturation between LGDL and flow channel was mostly related to liquid water flow velocity inside the flow channel, LGDL contact angle and porosity. Selamet et al. [46] used simultaneous neutron radiography and optical imaging to visualize two-phase transport behaviors in a PEMEC. They reported that higher temperature could improve water transport and the behavior of oxygen bubble was found to strongly influence the cell performance. An et al. [47] developed a mathematical model to investigate the effects of exchange current density, membrane thickness, and liquid saturation on the performance of an anion-exchange membrane water electrolyzer and their results showed that a decrease in the exchange membrane thickness could improve the cell performance. 
Although some experiments and numerical models have been carried out for investigating the gas/liquid two-phase transport phenomena in a PEMEC, most work is merely focused on the limited effects of cell parameters or treated the two-phase transport and performance model separately, and many fundamental issues for two-phase transport effects still remain. Therefore, a comprehensive mathematical model that addresses the two-phase transport dynamics and the associated effects on a PEMEC performance at different operating conditions is highly needed., The present model, which is developed based on the porous media flow theory and electrochemical relationships, provides new insights into the comprehensive effects of cell key parameters and two-phase transport on the PEMEC performance and efficiency. The coupling of two-phase transport and performance model, the capture of limiting current density, and cell efficiency evaluation are addressed in detail. In addition, the present model shows good agreement with recent experimental data and its effectiveness is validated. This study provides more fundamental understanding and quantitative analysis to the effects of gas/liquid two-phase transport on the PEMEC performance and facilitates the cell optimization and design.

\section{Model development}

\subsection{Gas/liquid two-phase transport equations in LGDL}

Based on the classical fluid flow theory, the conservation equations of mass and momentum in a porous media can be described by the following, which solve the gas and liquid transport phenomenon with two separate phase equations, respectively.

Mass (gas and liquid phases)

$\frac{\partial\left(\varepsilon \rho_{g}(1-s)\right)}{\partial t}+\nabla \cdot\left(\rho_{g} \boldsymbol{u}_{\boldsymbol{g}}\right)=0$ 
$\frac{\partial\left(\varepsilon \rho_{l} s\right)}{\partial t}+\nabla \cdot\left(\rho_{l} \boldsymbol{u}_{l}\right)=0$

Since the flow in the LGDLs is controlled by the capillary pressure and is considered to be laminar, the Darcy's law is applied to obtain the momentum conservation of gas and liquid phases.

Momentum (gas and liquid phases)

$\boldsymbol{u}_{\boldsymbol{g}}=-\frac{K k_{r g}}{\mu_{g}} \nabla p_{g}$

$\boldsymbol{u}_{\boldsymbol{l}}=-\frac{K k_{r l}}{\mu_{l}} \nabla p_{l}$

Where $\varepsilon$ is the porosity of porous media, $\rho$ is the fluid density, $s$ is the liquid saturation (defined as the ratio of the volume occupied by the liquid to the total void volume in a porous media and the saturation level can be used to quantify the liquid distribution or flooding degree in a porous media.), $t$ represents the time variable, $u$ is the fluid velocity vector, $K$ is the permeability of a porous media, $k_{r g}$ and $k_{r l}$ are relative permeability of gas or liquid phase in a porous media respectively, and $\mu$ is the fluid dynamic viscosity.

In the present model, several simplifying assumptions are needed. First, the steady state and isothermal conditions are incorporated into the two-phase model of LGDL, since the LGDL thickness is relatively small compared with the other dimensions of the PEMEC. Second, the CL is assumed to be infinitely thin and the electrochemical reaction only occurs at the interface between the LGDL and CL. Since a typical oxygen-liquid water two-phase flow occurs at the anode of PEMEC that contributes to most of the diffusion losses, the present model will only focus on the mass transport process inside the anode LGDLs without considering the transport effects in the CL and PEM. At the anode side of a PEMEC, liquid water enters through the channel and then diffuses through the porous LGDL to the reaction site in the CL, where liquid 
water is dissociated into electrons, protons, and oxygen. The produced oxygen flows back through the anode LGDL to the anode flow channel. Water oxidation reaction at the anode can be expressed as

$$
\mathrm{H}_{2} \mathrm{O} \rightarrow 2 \mathrm{H}^{+}+\frac{1}{2} \mathrm{O}_{2}+2 e^{-}
$$

To address the oxygen and liquid water distribution in the LGDL and the effect of two-phase transport on the cell performance, it is necessary to establish an effective gas/liquid two-phase transport model for the LGDL.

Based on the above classical two-phase conservation equations in a porous media and basic assumptions, a steady state gas/liquid two-phase model for the anode LGDL can be derived as the transient terms in Equation (1) and (2) are negligible.

Oxygen transport in the LGDL is considered first. A steady state mass conservation equation of gas phase can be expressed as

$\nabla \cdot\left(\rho_{O_{2}} \boldsymbol{u}_{\boldsymbol{O}_{2}}\right)=0$

Substituting Equation (3) into Equation (6), one obtains

$\nabla \cdot\left(-\frac{K k_{O_{2}}}{\mu_{O_{2}} / \rho_{O_{2}}} \nabla p_{O_{2}}\right)=0$

In a similar way, a steady state mass conservation equation of liquid water transport in the LGDL can be written as

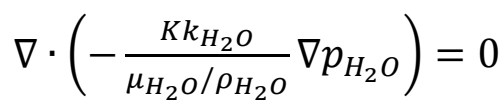

The oxygen and liquid water pressure inside the porous LGDL is related to capillary pressure, which can be defined as 


$$
p_{c}=p_{n w}-p_{w}=\left\{\begin{array}{c}
p_{\mathrm{O}_{2}}-p_{\mathrm{H}_{2} \mathrm{O}} \\
\left(0<\theta<90^{\circ}, \text { hydrophilic }\right) \\
p_{\mathrm{H}_{2} \mathrm{O}}-p_{\mathrm{O}_{2}} \\
\left(90^{\circ}<\theta<180^{\circ}, \text { hydrophobic }\right)
\end{array}\right.
$$

The capillary pressure can be expressed in detail, which is a function of liquid saturation, porosity, permeability, liquid surface tension, and contact angle in the LGDL.

$$
p_{c}=J(s)\left(\frac{\varepsilon}{K}\right)^{1 / 2} \sigma \cos \theta
$$

Where $\sigma$ is the surface tension, $\theta$ is the contact angle and $J(s)$ is the Leverett's function that is given by the following formula

$$
J(s)=\left\{\begin{array}{c}
1.417(1-s)-2.120(1-s)^{2}+1.263(1-s)^{3}, \\
\left(0<\theta<90^{\circ}, \text { hydrophilic }\right) \\
1.417 s-2.120 s^{2}+1.263 s^{3} \\
\left(90^{\circ}<\theta<180^{\circ}, \text { hydrophobic }\right)
\end{array}\right.
$$

For a hydrophilic LGDL, Equation (8) can be rewritten with the Equation (9) and Equation (10) as

$\nabla \cdot\left[\left(-\frac{K k_{\mathrm{H}_{2} \mathrm{O}}}{\mu_{\mathrm{H}_{2} \mathrm{O} / \rho_{\mathrm{H}_{2} \mathrm{O}}}}\right) \nabla p_{\mathrm{O}_{2}}\right]+\nabla \cdot\left\{\left(-\frac{K k_{\mathrm{H}_{2} \mathrm{O}}}{\mu_{\mathrm{H}_{2} \mathrm{O} / \rho_{\mathrm{H}_{2} \mathrm{O}} \mathrm{O}}}\right)\left[-\left(\frac{\varepsilon}{K}\right)^{0.5} \sigma \cos \theta\right] \nabla J(s)\right\}=0$

Where the relative permeability $(k)$ is respectively derived from [30]

$k_{\mathrm{H}_{2} \mathrm{O}}=s^{3}$

$$
k_{O_{2}}=(1-s)^{3}
$$

Lastly, the gas/liquid two-phase transport inside anode LGDL can be modeled based on Equations (7) and (12). Considering Equation (11), (13), and (14), oxygen and liquid water twophase transport equations inside the anode LGDL can be rewritten in the following form (for a hydrophilic LGDL): 


$$
\left\{\begin{array}{c}
\nabla \cdot\left(-\frac{K(1-s)^{3}}{\mu_{O_{2}} / \rho_{O_{2}}} \nabla p_{O_{2}}\right)=0 \\
\nabla \cdot\left[\left(-\frac{K s^{3}}{\mu_{H_{2} O} / \rho_{H_{2} O} O}\right) \nabla p_{O_{2}}\right]+ \\
\nabla \cdot\left\{\left(-\frac{K s^{3}}{\mu_{H_{2} O} / \rho_{H_{2} O} O}\right)\left[-\left(\frac{\varepsilon}{K}\right)^{0.5} \sigma \cos \theta\right] \nabla\left(1.417(1-s)-2.120(1-s)^{2}+1.263(1-s)^{3}\right)\right\}=0
\end{array}\right.
$$

\subsection{Electrochemical performance}

The electrochemical performance relationship for a PEMEC should consist of open circuit voltage, activation overpotential, diffusion overpotential, and ohmic loss. The primary formulas concerning the cell performance and efficiency modeling are listed in the following equations [48].

The open circuit voltage can be expressed as

$V_{o c v}=V_{0}+\frac{R T}{z F} \ln \left(\frac{\alpha_{H_{2}} \alpha_{O_{2}}^{0.5}}{\alpha_{H_{2}} \mathrm{O}}\right)$

Where the reversible voltage $V_{0}$ can be calculated by

$$
V_{0}=1.229-0.9 \times 10^{-3}(T-298.15)
$$

The activation overpotential [15] due to the electrochemical reaction and the diffusion overpotential can be calculated as

$$
\begin{aligned}
& V_{a c t}=\frac{R T_{a}}{\alpha_{a} F} \sinh ^{-1}\left(\frac{j}{2 s j_{0, a}}\right)+\frac{R T_{C}}{\alpha_{c} F} \sinh ^{-1}\left(\frac{j}{2 s j_{0, c}}\right) \\
& V_{\text {diff }}=\frac{R T_{a}}{4 F} \ln \left(\frac{C_{O_{2}, m}}{C_{O_{2}, m 0}}\right)+\frac{R T_{c}}{2 F} \ln \left(\frac{C_{H_{2}, m}}{C_{H_{2}, m 0}}\right)
\end{aligned}
$$

Where $R$ is the gas constant, $T$ is the operating temperature, $\alpha_{a}$ and $\alpha_{c}$ are the charge transfer coefficients at the anode and cathode, $F$ is the Faraday constant, $j$ is current density, $j_{0}$ is the exchange current density on the anode and cathode electrode, $s$ is the interfacial liquid saturation between the anode LGDL and CL, $C_{\mathrm{O}_{2}, m}$ and $C_{\mathrm{H}_{2}, m}$ are the oxygen and hydrogen concentrations 
at the interface of electrode and membrane, respectively. $C_{\mathrm{O}_{2}, m 0}$ and $C_{\mathrm{H}_{2}, m 0}$ indicate the reference values, which are provided in the reference[48].

The total ohmic loss can be expressed as

$V_{\text {ohm }}=\left(R_{\text {plate }}+R_{L G D L}+R_{P E M}+R_{\text {in }}\right) j A$

Where the PEM resistance contributes to most of the total ohmic loss, which can be calculated as

$R_{P E M}=\frac{\delta_{m} A}{\sigma_{m}}$

Here, $\delta_{m}$ is the PEM thickness and $\sigma_{m}$ is the PEM conductivity that is related to the humidification degree $\lambda$ and operating temperature $T$.

$\sigma_{m}=(0.005139 \lambda-0.00326) \exp \left[1268\left(\frac{1}{303}-\frac{1}{T}\right)\right]$

The resistances from the plate:

$R_{\text {plate } 1}=\rho_{p} \frac{L_{a b}}{A}, R_{\text {plate } 2}=\rho_{p} \frac{L_{b c}}{0.5 L_{i k} A}$

The resistances from the LGDL:

$R_{e 1}=\rho_{e} \frac{0.25 L_{k l}}{\delta L(1-\varepsilon)}, R_{e 2}=\rho_{e} \frac{\delta}{0.5 L_{i k} L(1-\varepsilon)}, R_{e 3}=\rho_{e} \frac{\delta}{0.5 L_{k l} L(1-\varepsilon)}$

The resistance from the interfacial effects is assumed to be $2 R_{e 2}$ that can better fit the experimental data.

$R_{\text {in }}=2 \rho_{e} \frac{\delta}{0.5 L_{i k} L(1-\varepsilon)}$

Where $\rho_{p}$ and $\rho_{e}$ is respectively the plate and LGDL material resistivity, $L_{a b}$ is the plate part thickness without flow channel, $L_{b c}$ is the flow channel height, $L_{i k}$ is the flow channel support width, $L_{k l}$ is the flow channel width, $L$ is the membrane electrode assembly (MEA) length, $\delta$ is the LGDL thickness, and $A$ is reaction area. The total resistances from plates and LGDLs can be obtained using an equivalent resistance model [48]. 
Finally, the entire overpotential relationship of a PEMEC, which is used to calculate the cell polarization curves, can be expressed as

$V=V_{o c v}+V_{a c t}+V_{d i f f}+V_{o h m}$

The efficiency of a PEMEC [47] can be defined as

$\eta=\frac{V_{\text {theoretical }}}{V_{\text {total }}}=\frac{V_{o c v}}{V_{o c v}+V_{a c t}+V_{\text {diff }}+V_{o h m}}$

\section{Modeling conditions}

Geometry and physicochemical parameters used as the basic conditions for the present modeling are listed in Table 1. In addition, since the flows in the LGDLs are mainly driven by the capillary pressure along the through-plane direction (x-direction), the present two-phase transport process can be simplified as one-dimensional. In order to properly solve the above gas/liquid two-phase transport equations, several boundary conditions are needed. First, the mass flux of oxygen $N_{\mathrm{O}_{2}}$ and liquid water $N_{\mathrm{H}_{2} \mathrm{O}}$ at the boundary is assumed to be only equal to the generation flux caused by the electrochemical reaction in the CL. Hence, the liquid water mass flux inside LGDL consumed by the electrochemical reaction can be calculated as follows

$N_{\mathrm{H}_{2} \mathrm{O}}=\frac{j M_{\mathrm{H}_{2} \mathrm{O}}}{2 \mathrm{~F}}$

The oxygen mass flux generated at the CL can be calculated as

$N_{O_{2}}=\frac{j M_{O_{2}}}{4 F}$

Second, the liquid water saturation at the interface of the LGDL and flow channel need to be determined. The interface liquid saturation is directly related to current density, porous structure parameters, and initial operating conditions, so it is difficult to calculate by using a typical 
theoretical formula. Based on some empirical approaches [31] [49], Equations (30-31) are used to estimate the interfacial saturation in the present model.

$$
\begin{aligned}
& \left\{\left.\frac{d s}{d x}\right|_{x=0}=\frac{\left.j\right|_{x=0}=s_{0} O}{2 F} \frac{\mu / \rho}{A \sigma \cos \theta(\varepsilon K)^{0.5}} /\left[s_{0}{ }^{3}\left(-0.966+3.338 s_{0}-3.789 s_{0}{ }^{2}\right)\right]\right. \\
& S_{0}=\frac{1.0}{1.0+a_{0} j}
\end{aligned}
$$

Where $a_{0}$ is an empirical coefficient that can be adjusted to better fit experimental data. According to the validation results shown in Figure 2, $a$ is equal to be 0.1 and the interfacial liquid saturation is calculated to be about 0.91 at a current density of $1.0 \mathrm{~A} / \mathrm{cm}^{2}$.

Third, the gas pressure at the interface of LGDL and flow channel is assumed to be equal to the operating pressure of electrolyzer cell.

$$
p_{O_{2}}=p
$$

\section{Results and discussion}

\subsection{Model solving and validation}

Gas/liquid two-phase transport equations inside the anode LGDL, as presented in Equation (15), are discretized into the algebraic equations along $\mathrm{x}$ direction by using the finite difference method and then they can be properly solved together with initial parameters and boundary conditions. The computation code is written and performed in FORTRAN 90. Grid points are set to 200 for $\mathrm{x}$ direction. As the number of grid points is adjusted to more than 200 , the numerical results are almost identical, which ensures that the results are independent on the grid points.

In order to use the new two-phase transport model, it needs to be first compared and validated with experimental studies. The available experimental data for the PEMEC performance can be 
found in the recent open papers $[50,51]$. In these experiments, the cell voltage is measured to be less than $2.0 \mathrm{~V}$ at $2.0 \mathrm{~A} / \mathrm{cm}^{2}$, which is representative of the voltage of a realistic commercial electrolyzer cell. Therefore, this data is appropriate for use in model validation. As shown in Figure 2a, in this case [50], a single PEMEC was operated at a temperature of $80^{\circ} \mathrm{C}$, an anode pressure of $1 \mathrm{~atm}$, a cathode pressure of $13.6 \mathrm{~atm}$, and a PEM thickness of 178 microns. It can be seen that the polarization curve simulated by the present model shows a good match to the experimental data. In another validation case [51], as shown in Figure 2b, the effects of PEM thickness on the polarization curve are simulated, including 60 microns and 90 microns. The modeling results also show good agreement with the experimental data, which demonstrates that the present model has the capability of simulating the cell performance under various operating conditions, and thus validates the new model developed in this study. The validation model is then used to investigate the effects of different operating parameters on two-phase transport properties and PEMEC performance and efficiency, including current density, contact angle, porosity and thickness of the LGDL and PEM thickness.

\subsection{Effects of LGDL contact angle}

A contact angle is used to measure the wettability of LGDL material, which has a significant impact on the liquid water and gas bubble transport inside the LGDL of a PEMEC. If the contact angle is larger than $90^{\circ}$, the LGDL surface is considered hydrophobic, but if the contact angle is smaller than $90^{\circ}$, the LGDL surface is considered hydrophilic. Further, it can be concluded that gas bubble dynamic behaviors on the solid surfaces are opposite of that of liquid droplet. Some studies $[45,52,53]$ indicated that hydrophilic pores help liquid water and gas bubble transport in a PEMEC, so this paper will focus on the hydrophilic LGDL. In addition, according to some studies [54-56], there might be different gas/liquid flow patterns inside the LGDL micro-pores 
at different operating conditions, which can affect the mass transport process and consequently affect the cell performance.

To quantify the effects of two-phase flow on the cell performance, it is necessary to simulate the liquid saturation distribution inside the LGDL. For an electrolyzer cell at given operating conditions, there is different liquid saturation distribution at different positions inside the LGDL because liquid water will be consumed when it gets close to the reaction area. In addition, the current density is a key operating parameter that influences the liquid saturation distribution. At higher current density, more water will be consumed at the interface of LGDL and CL, which is assumed to be the reaction area in this study, and the liquid saturation at the interface of flow channel and LGDL become smaller, according to Equations (28) and (31). As shown in Figure 3a, the liquid water saturation along the LGDL thickness direction depends on the current density. As expected, the liquid saturation decreases with increasing the current density with a significant change, especially near the interface between the LGDL and CL (at $x=200$ microns). For the LGDL with a porosity of 0.35 and contact angle of $20^{\circ}$, when the current density is equal to $2.0 \mathrm{~A} / \mathrm{cm}^{2}$, the liquid saturation inside the LGDL is predicted to be 0.82 at $\mathrm{x}=100$ microns, but when the current density is increased to the limiting value that is equal to $4.1 \mathrm{~A} / \mathrm{cm}^{2}$, the liquid saturation inside the LGDL is predicted to be 0.63 at 100 microns and it reaches minimum value at $\mathrm{x}=200$ microns. It can be estimated that as the current density further increases, the liquid saturation will decrease more rapidly and arrive at the minimum in front of the interface of LGDL and CL, where $\mathrm{x}$ should be less than 200 microns. This is because the liquid saturation at the interface of flow channel and LGDL becomes small at high current density according to Equation (31). In addition, it is also worthwhile to note that if the LGDL thickness is set to a higher value, the limiting current density will be less than $4.1 \mathrm{~A} / \mathrm{cm}^{2}$. 
To understand the effects of contact angle on the liquid saturation distribution inside the LGDL, three different cases corresponding to contact angles of $20^{\circ}, 60^{\circ}$ and $80^{\circ}$ are simulated while the current density is set to $2.0 \mathrm{~A} / \mathrm{cm}^{2}$ and the LGDL porosity is set to 0.35 , as shown in Figure $3 \mathrm{~b}$. In these cases, the interfacial saturation between flow channel and LGDL is equal to 0.83 at a current density of $2.0 \mathrm{~A} / \mathrm{cm}^{2}$. For the first case, the contact angle is equal to $20^{\circ}$, which means the LGDL exhibits strong hydrophilic properties. In Figure $3 b$, it can be seen that the liquid saturation has only minor changes along the LGDL thickness direction for a contact angle of $20^{\circ}$ and the saturation values are almost identical. As the contact angle increases to $60^{\circ}$, the changes slightly become significant but still not very obvious. The liquid saturation is found to decrease significantly along the LGDL thickness for larger contact angles. For example, for a contact angle of $80^{\circ}$, the liquid saturation at $\mathrm{x}=200$ is 0.44 and is $47 \%$ less than at $\mathrm{x}=0$. The results indicate that, on the one hand, a more hydrophilic LGDL is beneficial to liquid water transport, while on the other hand, the liquid saturation is more sensitive to contact angle variation under higher contact angle conditions.

As presented above, the contact angles have a significant impact on the liquid water transport inside the LGDL and the mass transport plays an important role in the cell performance and efficiency, therefore the changes in contact angle can be of importance to the cell. As shown in Figure 4 , the effects of the contact angle including $20^{\circ}, 60^{\circ}$, and $80^{\circ}$ on the cell performance and efficiency are examined. The polarization curves are observed to be similar for different contact angle conditions at relative low current density. However, these curves become different as the current density increases. For instance, at a current density of $1.0 \mathrm{~A} / \mathrm{cm}^{2}$, the voltage increases only by 0.01 as the contact angle increases from $20^{\circ}$ to $60^{\circ}$, and at a current density of $2.0 \mathrm{~A} / \mathrm{cm}^{2}$, the cell voltage increases by 0.07 as the contact angle increases from $20^{\circ}$ to $80^{\circ}$. However, as the 
current density gradually increases to higher values, there will be a sudden increase in cell voltage and a sudden decrease in cell efficiency. It can be found that the inflection points of the polarization curves depend on the LGDL contact angle. For a LGDL porosity of 0.35 , the limiting current density for $20^{\circ}$ is predicted to be around $4.1 \mathrm{~A} / \mathrm{cm}^{2}$. While the contact angle increases to $80^{\circ}$, the limiting current density is significantly less than that for $20^{\circ}$. This phenomenon can be attributed to less liquid saturation in the LGDL for a higher contact angle. The above results show that as the contact angle increases from $20^{\circ}$ to $80^{\circ}$, the electrolyzer cell voltage increases and the efficiency decreases. Meanwhile, the results also suggest that larger contact angle has a greater effect on the performance and efficiency of electrolyzer cell.

\subsection{Effects of LGDL porosity}

Porosity is one of the most important parameters for two-phase transport inside the LGDL and it is defined as the ratio of the volume of all pores to the total volume of a LGDL. In a real PEMEC, any change in LGDL morphology or composition, even liquid water distribution might result in a porosity change. At the anode, liquid water diffuses through the LGDL to the catalyst layer and the produced oxygen flows back through the LGDL to the flow channel, which is directly controlled by LGDL structure properties, such as porosity. Therefore, a change in LGDL porosity will have a great influence on the gas-liquid transport process and the performance and efficiency of the electrolyzer cell. The three-dimensional result in Figure 5a shows the effects of current density on the liquid saturation distribution along the LGDL thickness direction. In this case, the LGDL porosity is set to 0.55 while the contact angle is equal to $80^{\circ}$. It can be seen that the minimum saturation value can be obtained at the interface of the LGDL and CL (at $x=200$ ) when the current density is equal to $3.55 \mathrm{~A} / \mathrm{cm}^{2}$. Compared with the result in Figure $3 \mathrm{a}$, the limiting current density decreases due to the change in LGDL contact angle and porosity. One 
reason is that there is less liquid water in the LGDL with higher contact angle and a smaller current density is needed, as shown in Figure $3 b$.

On the other hand, as the porosity increases, the liquid saturation distribution along the LGDL thickness direction also will have a significant change. As shown in Figure 5b, for a fixed current density of $2.0 \mathrm{~A} / \mathrm{cm}^{2}$, the effects of LGDL porosity on the liquid water saturation along the LGDL thickness direction are investigated, considering three different porosity values responding to $0.35,0.45$ and 0.55 . In Figure $5 \mathrm{~b}$, it can be seen that the liquid water saturation significantly increases as the porosity increases from 0.35 to 0.55 . This is due to the fact that a higher porosity implies higher permeability that allows liquid water to pass through the LGDL more easily. At the interface of LGDL and CL ( $\mathrm{x}=200$ microns), the saturation increases by $82 \%$ when the porosity increases from 0.35 to 0.55 . Likewise, if the current density is adjusted, a similar change in liquid saturation can be obtained. Therefore, it can be concluded that there is more liquid water inside the LGDL with higher porosity, which means higher limiting current density is needed.

In the present model, according to Equation (15) and (30), the porosity not only has a direct impact on the saturation distribution, but also influences the boundary conditions, which will consequently affect the cell performance and efficiency. As shown in Figure 6, the cell polarization and efficiency curves are plotted to understand the effects of the porosity on the cell performance and efficiency and the contact angle is set to $80^{\circ}$. For a porosity of 0.35 , the cell voltage increase significantly as the current density increases. At the low current density, the activation overpotential and ohmic loss contribute to most of the cell voltage. As the current density increase to a limit value (around $2.1 \mathrm{~A} / \mathrm{cm}^{2}$ ), there will be a sudden increase in voltage, which is attributed to high diffusion overpotential caused by two-phase transport. For a higher 
porosity such as 0.55 , as expected, it can be seen that the limiting current density is increased to around $3.5 \mathrm{~A} / \mathrm{cm}^{2}$ because there is more liquid water in the reaction area. On the whole, the cell voltage decreases with increasing LGDL porosity and the cell efficiency increases with increasing LGDL porosity, which means a higher porosity can improve the cell performance and efficiency. Furthermore, it also can be found that, as the porosity increases above 0.45, the effects of porosity variation on the voltage and efficiency under low current density are very small. For instance, at a current density of $1.5 \mathrm{~A} / \mathrm{cm}^{2}$, the voltage at a porosity of 0.45 is equal to $1.864 \mathrm{~V}$ and the voltage at a porosity of 0.55 is equal to $1.858 \mathrm{~V}$.

\subsection{Effects of LGDL thickness and PEM thickness}

The new two-phase model is developed to investigate the effects of LGDL thickness and PEM thickness on the cell performance and efficiency. As the effect of two-phase transport is considered, effects of the LGDL thickness and PEM thickness on the cell performance might be different from those of a single phase transport model. For a practical PEMEC, LGDL thickness and PEM thickness may vary widely for different cell designs, which will affect the mass transport and ohmic loss of electrolyzer cell and consequently affect the cell performance. As shown in Figure 7, the effects of LGDL thickness on the cell performance and efficiency is examined at a contact angle of $80^{\circ}$ and a LGDL porosity of 0.35 . At the low current density, the polarization curves are observed to be similar for three kinds of LGDL thicknesses. However, at the higher current density, the polarization curves are different for different LGDL thicknesses and the voltage for a 200 micron LGDL is much greater than for a 50 microns LGDL. These phenomena show that a thinner LGDL can improve mass transport and consequently improve the cell performance and efficiency, which has been demonstrated with thin/well-tunable LGDLs, developed in our group[57-59]. In addition, for a fixed LGDL thickness, there will be a sudden 
change in voltage and efficiency as the current density increases. It can be seen that the limiting current density for a polarization curve with a LGDL thickness of 50 microns is predicted to be around $3.7 \mathrm{~A} / \mathrm{cm}^{2}$. As the LGDL thickness increases, the limiting current density becomes significantly smaller, $2.8 \mathrm{~A} / \mathrm{cm}^{2}$ for a LGDL thickness of 100 microns and $2.1 \mathrm{~A} / \mathrm{cm}^{2}$ for a LGDL thickness of 200 microns. Accordingly, a thick LGDL will have a more significant impact on the liquid water transport of electrolyzer cell because it can be more difficult for liquid water to diffuse into reaction site inside a thick LGDL, especially at a high current density.

In order to illustrate the effects of PEM thickness on the cell performance, different PEM thicknesses of 50 microns, 100 microns, and 200 microns are investigated using the new twophase model. The LGDL thickness is set at 200 microns. The porosity and contact angle of LGDL is 0.35 and $80^{\circ}$. The polarization and efficiency curves for three types of PEMs are plotted in Figure 8. It can be observed that increasing the PEM thickness will result in a significant increase in cell voltage and decrease in cell efficiency. For instance, when the PEM thickness is changed from 50 microns to 200 microns, the total cell voltage is found to be increased by around $0.12 \mathrm{~V}$ at $1.5 \mathrm{~A} / \mathrm{cm}^{2}$. As two-phase transport is considered, there is also a sudden change in voltage and efficiency with increasing the current density. However, it can be seen that the inflection point is the same for the PEMs with different thicknesses and the limiting current density values are around $2.1 \mathrm{~A} / \mathrm{cm}^{2}$, which is the same as that with a LGDL thickness of 200-micron case. This is due to the fact that the change in PEM thickness has no impact on the liquid saturation distribution and two-phase transport process inside the LGDL.

\section{Conclusions}


In this study, a two-phase transport model for a PEMEC has been established based on the porous media flow theory and electrochemical relationships to investigate the effects of twophase transport on the cell performance, and provide new insights into the cell polarization curve and limiting current density. Compared to previous models, the present two-phase model is capable of simulating the effects of several important parameters, including the current density, contact angle, porosity, and thickness, on the liquid water transport/saturation, voltage and efficiency in a PEMEC. It has been shown that an increased contact angle in LGDLs will raise the cell voltage and decrease cell efficiency, but an increased LGDL porosity will decrease the cell voltage and enhance cell efficiency. As the current density increases and reaches the limiting current density, sudden changes in the PEMEC voltage and efficiency are captured. This new phenomenon is caused by two-phase transport inside the LGDL, and is closely related to its contact angle, porosity and thickness. In addition, the changes in LGDL thickness and membrane thickness also have significant impacts on the cell performance and efficiency due to their contributions to the mass transport and ohmic resistances. A thin LGDL and/or membrane will decrease the diffusion overpotential and ohmic loss and consequently improve the cell performance and efficiency. The present model has been validated with recent experimental data, and will provide useful information for optimizing the PEMEC design, performance and efficiency. Further optimization studies such as temperature gradient effects and micro-scale flow through porous media will be performed in the future research work.

\section{Acknowledgements}

The authors greatly appreciate the support from U.S. Department of Energy's National Energy Technology Laboratory under Award DE-FE0011585 and the Center for Nanophase Materials 
Sciences, which is sponsored at Oak Ridge National Laboratory by the Scientific User Facilities Division, Office of Basic Energy Sciences, U.S. Department of Energy. The authors also wish to express their appreciation to Scott T. Retterer, David A. Cullen, Stuart Steen, and Rong Chen for their help. 


\section{List of symbols}

\begin{tabular}{|c|c|}
\hline$A$ & Reaction area, $\mathrm{cm}^{2}$ \\
\hline$a_{0}$ & Empirical coefficient to estimate the interfacial saturation \\
\hline$C_{H_{2}, m}$ & Hydrogen concentration at the interface of electrode and PEM, $\mathrm{mol} / \mathrm{cm}^{3}$ \\
\hline$C_{i, m 0}$ & Reference concentration, $\mathrm{mol} / \mathrm{cm}^{3}$ \\
\hline$C_{O_{2}, m}$ & Oxygen concentration at the interface of electrode and PEM, $\mathrm{mol} / \mathrm{cm}^{3}$ \\
\hline$j$ & Current density, $\mathrm{A} / \mathrm{cm}^{2}$ \\
\hline$j_{0}$ & Exchange current density, $\mathrm{A} / \mathrm{cm}^{2}$ \\
\hline$K$ & Permeability \\
\hline$k_{r}$ & Relative permeability \\
\hline$L_{i j}$ & Cell component size, $\mathrm{cm}$ \\
\hline$M$ & Molar mass, g/mol \\
\hline$N$ & Fluid mass flux, mol/s \\
\hline$p$ & Pressure, atm \\
\hline$R_{e}$ & LGDL part resistance, $\Omega$ \\
\hline$R_{\text {in }}$ & Total interfacial resistance, $\Omega$ \\
\hline$R_{L G D L}$ & LGDL resistance, $\Omega$ \\
\hline$R_{P E M}$ & PEM resistance, $\Omega$ \\
\hline$R_{\text {plate }}$ & Plate resistance, $\Omega$ \\
\hline$s$ & Liquid saturation \\
\hline$s_{0}$ & Interfacial liquid saturation \\
\hline$t$ & Time, s \\
\hline$T$ & Temperature, $\mathrm{K}$ \\
\hline $\boldsymbol{u}$ & Fluid velocity vector \\
\hline$V$ & Voltage or overpotential, V \\
\hline$V_{0}$ & Reversible voltage, $\mathrm{V}$ \\
\hline$V_{s}$ & Overpotential due to activation and diffusion, atm \\
\hline$x$ & Distance along the LGDL thickness direction, micron \\
\hline$z$ & Mole number of electrons \\
\hline
\end{tabular}


Greek

$\alpha \quad$ Charge transfer coefficient, atm

$\alpha_{i} \quad$ Activity of species

$\varepsilon \quad$ Porosity

$\eta \quad$ Efficiency

$\theta \quad$ Contact angle, degree $\left(^{\circ}\right)$

$\mu \quad$ Fluid dynamic viscosity, $\mathrm{N} \mathrm{S} / \mathrm{cm}^{2}$

$\rho \quad$ Resistivity, $\Omega \mathrm{cm}$ or Fluid density, $\mathrm{kg} / \mathrm{cm}^{3}$

$\sigma \quad$ Surface tension, N/cm

$\sigma_{m} \quad$ PEM conductivity

$\delta_{m} \quad$ PEM thickness, micron

$\lambda \quad$ PEM humidification degree

Superscripts and subscripts

a $\quad$ Anode

c Capillary or cathode

$g \quad$ Gas phase

$\mathrm{H}_{2} \mathrm{O} \quad$ Liquid water

$i \quad$ Species index

$l \quad$ Liquid phase

nw Non-wetting phase

$\mathrm{O}_{2} \quad$ Oxygen

$O C V \quad$ Open circuit voltage

ohm Ohmic loss

$w \quad$ Wetting phase

$x \quad$ LGDL thickness direction (X axis)

Constants

$\rho_{\mathrm{H}_{2} \mathrm{O}} \quad$ Water density, $1.0 \mathrm{~g} / \mathrm{cm}^{3}$

$\mu_{\mathrm{H}_{2} \mathrm{O}} \quad$ Water dynamic viscosity, $3.5 \times 10^{-7}{\mathrm{~N} \mathrm{~S} / \mathrm{cm}^{2}}^{2}$ 
F Faraday constant, $96485.0 \mathrm{C} / \mathrm{mol}$

$M_{m, H_{2} \mathrm{O}} \quad$ Water molar mass, $18 \mathrm{~g} / \mathrm{mol}$

$R \quad$ Gas constant, $8.314 \mathrm{~J} / \mathrm{mol} \mathrm{K}$ 


\section{References}

[1] Millet P, Mbemba N, Grigoriev SA, Fateev VN, Aukauloo A, Etievant C. Electrochemical performances of PEM water electrolysis cells and perspectives. International Journal of Hydrogen Energy. 2011;36(6):4134-42.

[2] Carmo M, Fritz DL, Mergel J, Stolten D. A comprehensive review on PEM water electrolysis. International Journal of Hydrogen Energy. 2013;38(12):4901-34.

[3] Steen SM, Zhang F-Y. In-situ and Ex-situ Characterizations of Electrode Interfaces in Energy Storage Electrolyzers. ECS Transactions. 2014;59(1):95-102.

[4] Briguglio N, Brunaccini G, Siracusano S, Randazzo N, Dispenza G, Ferraro M, et al. Design and testing of a compact PEM electrolyzer system. International Journal of Hydrogen Energy. 2013;38(26):11519-29.

[5] Mo J, Steen SM, Zhang F-Y, Toops TJ, Brady MP, Green JB. Electrochemical investigation of stainless steel corrosion in a proton exchange membrane electrolyzer cell. International Journal of Hydrogen Energy. 2015;40(36):12506-11.

[6] Wang Y, Chen KS, Mishler J, Cho SC, Adroher XC. A review of polymer electrolyte membrane fuel cells: technology, applications, and needs on fundamental research. Applied Energy. 2011;88(4):981-1007.

[7] Litster S, Djilali N. Two-phase transport in porous gas diffusion electrodes. Transport phenomena in fuel cells: WIT Press; 2005. p. 175-213.

[8] Zheng L, Srouji A, Turhan A, Mench M. Computational exploration of ultra-high current PEFC operation with porous flow field. Journal of the Electrochemical Society. 2012;159(7):F267-F77.

[9] Mench MM. Fuel cell engines: John Wiley \& Sons; 2008.

[10] Mo J, Dehoff RR, Peter WH, Toops TJ, Green JB, Zhang FY. Additive manufacturing of liquid/gas diffusion layers for low-cost and high-efficiency hydrogen production. International Journal of Hydrogen Energy. 2016;41(4):3128-35.

[11] Arvay A, French J, Wang JC, Peng XH, Kannan AM. Nature inspired flow field designs for proton exchange membrane fuel cell. International Journal of Hydrogen Energy. 2013;38(9):3717-26.

[12] Arvay A, Ahmed A, Peng X-H, Kannan A. Convergence criteria establishment for 3D simulation of proton exchange membrane fuel cell. international journal of hydrogen energy. 2012;37(3):2482-9.

[13] Wang C, Cheng P. A multiphase mixture model for multiphase, multicomponent transport in capillary porous media-I. Model development. International journal of heat and mass transfer. 1996;39(17):3607-18.

[14] Wu H-W. A review of recent development: Transport and performance modeling of PEM fuel cells. Applied Energy. 2016;165:81-106.

[15] Wang Z, Wang C, Chen K. Two-phase flow and transport in the air cathode of proton exchange membrane fuel cells. Journal of Power Sources. 2001;94(1):40-50.

[16] Meng H, Wang C-Y. Model of two-phase flow and flooding dynamics in polymer electrolyte fuel cells. Journal of the Electrochemical Society. 2005;152(9):A1733-A41.

[17] Pasaogullari U, Wang C-Y. Two-phase modeling and flooding prediction of polymer electrolyte fuel cells. Journal of The Electrochemical Society. 2005;152(2):A380-A90. 
[18] Wang Y. Modeling of two-phase transport in the diffusion media of polymer electrolyte fuel cells. Journal of Power Sources. 2008;185(1):261-71.

[19] Kumbur E, Sharp K, Mench M. On the effectiveness of Leverett approach for describing the water transport in fuel cell diffusion media. Journal of Power Sources. 2007;168(2):356-68.

[20] Armijo KM, Carey VP. Impact of Microchannel Boundary Conditions and Porosity Variation on Diffusion Layer Saturation and Transport in Fuel Cells. J Fuel Cell Sci Tech. 2012;9(4).

[21] Han B, Yu J, Meng H. Lattice Boltzmann simulations of liquid droplets development and interaction in a gas channel of a proton exchange membrane fuel cell. Journal of Power Sources. 2012;202:175-83.

[22] Friedmann R, Van Nguyen T. Optimization of the microstructure of the cathode catalyst layer of a PEMFC for two-phase flow. Journal of The Electrochemical Society. 2010;157(2):B260-B5.

[23] Lin G, Van Nguyen T. A two-dimensional two-phase model of a PEM fuel cell. Journal of the Electrochemical Society. 2006;153(2):A372-A82.

[24] Berning T, Lu DM, Djilali N. Three-dimensional computational analysis of transport phenomena in a PEM fuel cell. Journal of power sources. 2002;106(1):284-94.

[25] Ding Y, Bi XT, Wilkinson DP. Numerical investigation of the impact of two-phase flow maldistribution on PEM fuel cell performance. International Journal of Hydrogen Energy. 2014;39(1):469-80.

[26] Li A, Chan SH. Understanding the role of cathode structure and property on water management and electrochemical performance of a PEM fuel cell. International Journal of Hydrogen Energy. 2013;38(27):11988-95.

[27] Laoun B, Naceur MW, Khellaf A, Kannan AM. Global sensitivity analysis of proton exchange membrane fuel cell model. International Journal of Hydrogen Energy. 2016;41(22):9521-8.

[28] Larbi B, Alimi W, Chouikh R, Guizani A. Effect of porosity and pressure on the PEM fuel cell performance. International Journal of Hydrogen Energy. 2013;38(20):8542-9.

[29] Salva JA, Iranzo A, Rosa F, Tapia E, Lopez E, Isorna F. Optimization of a PEM fuel cell operating conditions: Obtaining the maximum performance polarization curve. International Journal of Hydrogen Energy. 2016. DOI: 10.1016/j.ijhydene.2016.03.136.

[30] Meng H. Numerical studies of liquid water behaviors in PEM fuel cell cathode considering transport across different porous layers. International Journal of Hydrogen Energy. 2010;35(11):5569-79.

[31] Wang Z, Wang C. Mathematical modeling of liquid-feed direct methanol fuel cells. Journal of The Electrochemical Society. 2003;150(4):A508-A19.

[32] Yan T, Jen T-C. Two-phase flow modeling of liquid-feed direct methanol fuel cell. International Journal of Heat and Mass Transfer. 2008;51(5):1192-204.

[33] Yang W, Zhao T. Numerical investigations of effect of membrane electrode assembly structure on water crossover in a liquid-feed direct methanol fuel cell. Journal of Power Sources. 2009;188(2):433-46.

[34] Matar S, Ge J, Liu H. Modeling the cathode catalyst layer of a Direct Methanol Fuel Cell. Journal of Power Sources. 2013;243:195-202. 
[35] Ge J, Liu H. A three-dimensional two-phase flow model for a liquid-fed direct methanol fuel cell. Journal of Power Sources. 2007;163(2):907-15.

[36] Yang WW, Zhao TS, Wu QX. Modeling of a passive DMFC operating with neat methanol. Fuel \& Energy Abstracts. 2011;36(11):6899-913.

[37] Ito H, Maeda T, Nakano A, Hasegawa Y, Yokoi N, Hwang C, et al. Effect of flow regime of circulating water on a proton exchange membrane electrolyzer. international journal of hydrogen energy. 2010;35(18):9550-60.

[38] Nie J, Chen Y. Numerical modeling of three-dimensional two-phase gas-liquid flow in the flow field plate of a PEM electrolysis cell. international journal of hydrogen energy. 2010;35(8):3183-97.

[39] Selamet O, Pasaogullari U, Spernjak D, Hussey D, Jacobson D, Mat M. Two-phase flow in a proton exchange membrane electrolyzer visualized in situ by simultaneous neutron radiography and optical imaging. international journal of hydrogen energy. 2013;38(14):5823-35.

[40] Derhoumi Z, Mandin P, Roustan H, Wüthrich R. Experimental investigation of twophase electrolysis processes: comparison with or without gravity. Journal of Applied Electrochemistry. 2013;43(12):1145-61.

[41] Olesen AC, Rømer C, Kær SK. A numerical study of the gas-liquid, two-phase flow maldistribution in the anode of a high pressure PEM water electrolysis cell. International Journal of Hydrogen Energy. 2016;41(1):52-68.

[42] Langemann M, Fritz DL, Müller M, Stolten D. Validation and characterization of suitable materials for bipolar plates in PEM water electrolysis. International Journal of Hydrogen Energy. 2015;40(35):11385-91.

[43] Grigoriev SA, Kalinnikov AA. Mathematical modeling and experimental study of the performance of PEM water electrolysis cell with different loadings of platinum metals in electrocatalytic layers. International Journal of Hydrogen Energy. 2016. DOI: 10.1016/j.ijhydene.2016.09.058.

[44] Kúš P, Ostroverkh A, Ševčíková K, Khalakhan I, Fiala R, Skála T, et al. Magnetron sputtered Ir thin film on TiC-based support sublayer as low-loading anode catalyst for proton exchange membrane water electrolysis. International Journal of Hydrogen Energy. 2016;41(34):15124-32.

[45] Grigoriev S, Kalinnikov A, Millet P, Porembsky V, Fateev V. Mathematical modeling of high-pressure PEM water electrolysis. Journal of applied electrochemistry. 2010;40(5):921-32.

[46] Selamet OF, Pasaogullari U, Spernjak D, Hussey DS, Jacobson DL, Mat M. In Situ TwoPhase Flow Investigation of Proton Exchange Membrane (PEM) Electrolyzer by Simultaneous Optical and Neutron Imaging. ECS Transactions. 2011;41(1):349-62.

[47] An L, Zhao T, Chai Z, Tan P, Zeng L. Mathematical modeling of an anion-exchange membrane water electrolyzer for hydrogen production. International Journal of Hydrogen Energy. 2014;39(35):19869-76.

[48] Han B, Steen III SM, Mo J, Zhang FY. Electrochemical performance modeling of a proton exchange membrane electrolyzer cell for hydrogen energy. International Journal of Hydrogen Energy. 2015;40(22):7006-16. 
[49] Pasaogullari U, Wang C. Liquid water transport in gas diffusion layer of polymer electrolyte fuel cells. Journal of the Electrochemical Society. 2004;151(3):A399-A406.

[50] Debe M, Hendricks S, Vernstrom G, Meyers M, Brostrom M, Stephens M, et al. Initial performance and durability of ultra-low loaded NSTF electrodes for PEM electrolyzers. Journal of the Electrochemical Society. 2012;159(6):K165-K76.

[51] Ayers KE, Capuano C, Anderson EB. Recent advances in cell cost and efficiency for PEM-based water electrolysis. ECS Transactions. 2012;41(10):15-22.

[52] Mo J, Steen III SM, Han B, Zhang F-Y. High-speed and micro-scale measurements of flow and reaction dynamics for sustainable energy storage. AIAA 2015-3913. 13th International Energy Conversion Engineering Conference. Orlando, FL,USA2015.

[53] Mancusi E, Fontana É, de Souza AAU, de Souza SMGU. Numerical study of two-phase flow patterns in the gas channel of PEM fuel cells with tapered flow field design. International Journal of Hydrogen Energy. 2014;39(5):2261-73.

[54] Triplett K, Ghiaasiaan S, Abdel-Khalik S, Sadowski D. Gas-liquid two-phase flow in microchannels Part I: two-phase flow patterns. International Journal of Multiphase Flow. 1999;25(3):377-94.

[55] Bozorgnezhad A, Shams M, Kanani H, Hasheminasab M, Ahmadi G. Two-phase flow and droplet behavior in microchannels of PEM fuel cell. International Journal of Hydrogen Energy. 2016;41(42):19164-81.

[56] Ito H, Maeda T, Nakano A, Hwang CM, Ishida M, Kato A, et al. Experimental study on porous current collectors of PEM electrolyzers. International journal of hydrogen energy. 2012;37(9):7418-28.

[57] Mo J, Kang Z, Yang G, Retterer ST, Cullen DA, Toops TJ, et al. Thin liquid/gas diffusion layers for high-efficiency hydrogen production from water splitting. Applied Energy. 2016;177:817-22.

[58] Kang Z, Mo J, Yang G, Cullen DA, Retterer ST, Toops TJ, et al. Investigation of thin/well-tunable liquid/gas diffusion layers exhibiting superior multifunctional performance in low-temperature electrolytic water splitting. Energy \& Environmental Science. 2016. DOI: 10.1039/c6ee02368a.

[59] Mo J, Kang Z, Retterer ST, Cullen DA, Toops TJ, Jr. JBG, et al. Discovery of true electrochemical reactions for ultrahigh catalyst mass activity in water splitting. Science Advances. 2016;2(11):e1600690. 


\section{List of Tables}

Table 1: Geometry and physicochemical parameters for PEMEC modeling 
Table1

\begin{tabular}{ll}
\hline Description, symbol & Value, unit \\
\hline MEA active area, A & $5.0 \mathrm{~cm}^{2}$ \\
Flow channel thickness, $H_{c h}$ & $0.5 \mathrm{~mm}$ \\
LGDL thickness, $\delta$ & $200 \mu \mathrm{m}$ \\
PEM thickness, $\delta_{m}$ & $178 \mu \mathrm{m}$ \\
LGDL average pore diameter, d & $30 \mu \mathrm{m}$ \\
LGDL porosity, $\varepsilon$ & $0.35 / 0.45 / 0.55$ \\
LGDL resistivity & $5.0 \times 10^{-3} \mathrm{ohm} \mathrm{cm}$ \\
Operating pressure, $\mathrm{P}$ & $\mathrm{Anode}: 1 \mathrm{~atm}$ \\
Operating temperature, T & $\mathrm{Cathode:} 13.6 \mathrm{~atm}$ \\
Water molar mass, $M_{\mathrm{H}_{2} O}$ & $80^{\circ} \mathrm{C}$ \\
Oxygen molar mass, $M_{\mathrm{O}_{2}}$ & $18 \mathrm{~g} / \mathrm{mol}$ \\
Faraday constant, $\mathrm{F}$ & $32 \mathrm{~g} / \mathrm{mol}$ \\
Contact angle, $\theta$ & $96487.0 \mathrm{C} / \mathrm{mol}$ \\
Liquid water dynamic viscosity, $\mu_{\mathrm{H}_{2} O} \mathrm{O}$ & $3.55 \times 10^{-4} \mathrm{~N} \mathrm{~s} / \mathrm{m}^{2}$ \\
Liquid water density, $\rho_{\mathrm{H}_{2} O} \mathrm{O}$ & $1000 \mathrm{~kg} / \mathrm{m}^{3}$ \\
Oxygen dynamic viscosity, $\mu_{\mathrm{O}_{2}}$ & $2.34 \times 10^{-5} \mathrm{~N} \mathrm{~s} / \mathrm{m}^{2}$ \\
Oxygen density, $\rho_{\mathrm{O}_{2}}$ & $1.0 \mathrm{~kg} / \mathrm{m}^{3}$ \\
Surface tension, $\sigma$ & $0.0625 \mathrm{~N} / \mathrm{m}$ \\
\hline & \\
\hline
\end{tabular}




\section{List of Figures}

Figure 1: Three dimensional geometrical schematic of a PEMEC

Figure 2: Comparison and validation between the experimental data and present model (a) case1 (b) case2

Figure 3: (a) Effects of current density on the liquid water saturation along the LGDL thickness direction (porosity: 0.35); (b) Effects of LGDL contact angle on the liquid water saturation distribution at a current density of $2.0 \mathrm{~A} / \mathrm{cm} 2$

Figure 4: Effects of LGDL contact angle on the cell performance and efficiency

Figure 5: (a) Effects of current density on the liquid water saturation along the LGDL thickness direction (porosity: 0.55); (b) Effects of LGDL porosity on the liquid water saturation distribution at a current density of $2.0 \mathrm{~A} / \mathrm{cm} 2$

Figure 6: Effects of LGDL porosity on the cell performance and efficiency

Figure 7: Effects of LGDL thickness on the cell performance and efficiency

Figure 8: Effects of PEM thickness on the cell performance and efficiency 


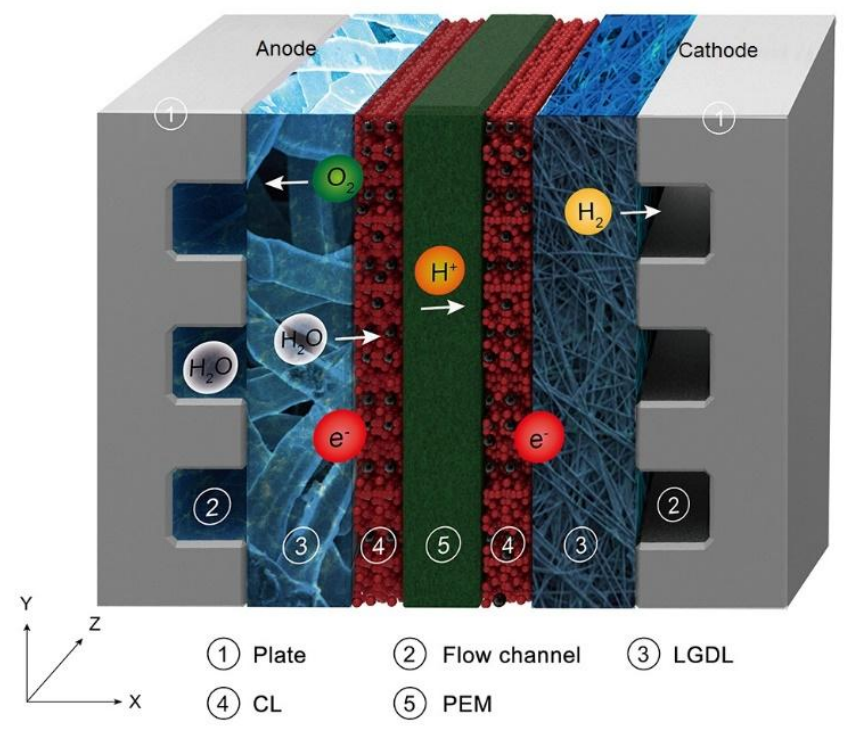

Figure 1 


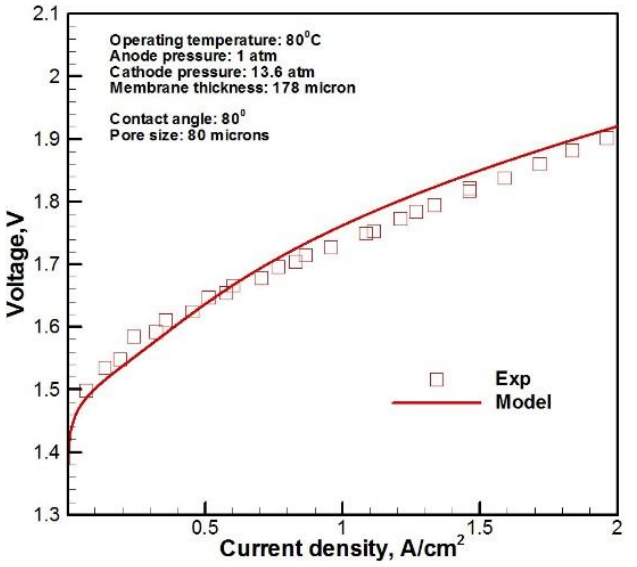

(a)

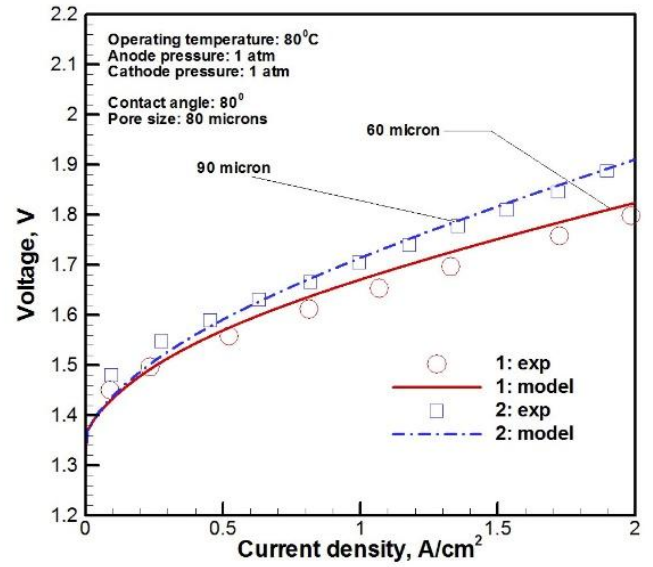

(b)

Figure 2 


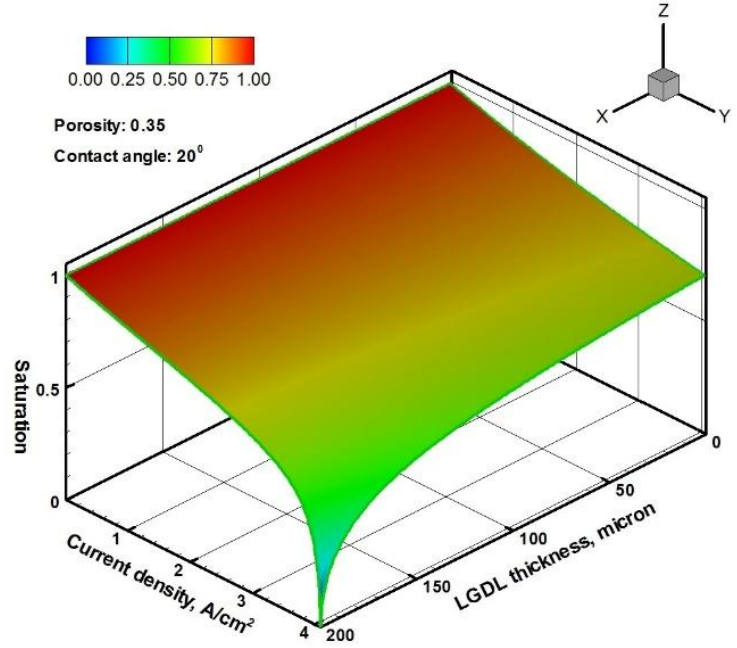

(a)

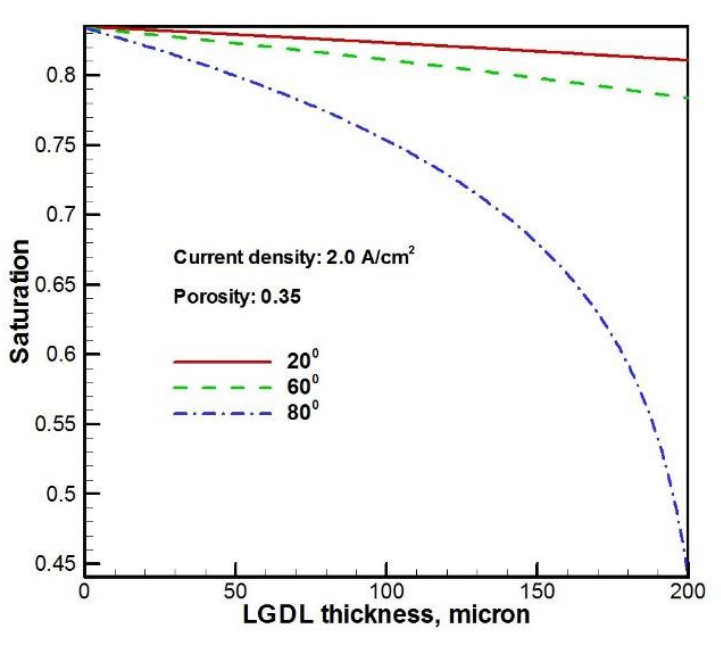

(b)

Figure 3 


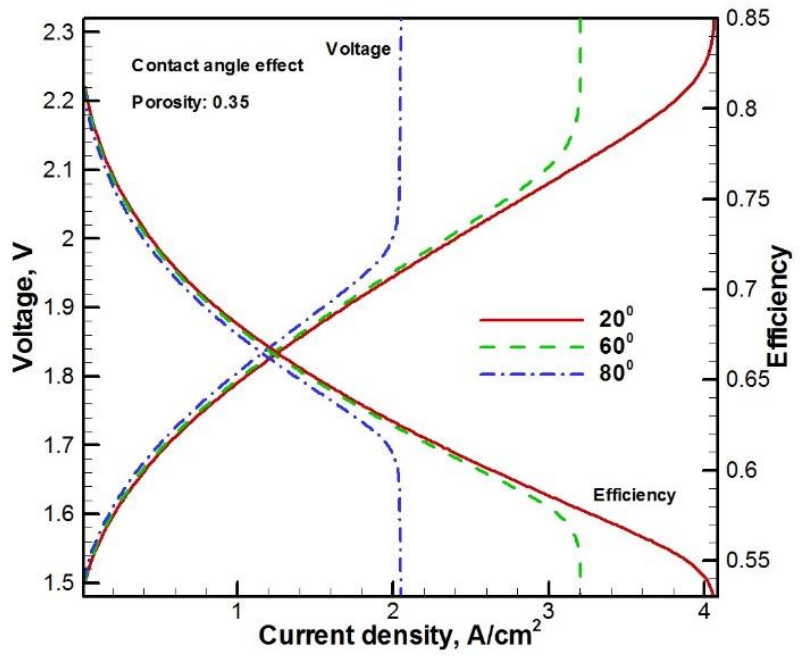

Figure 4 


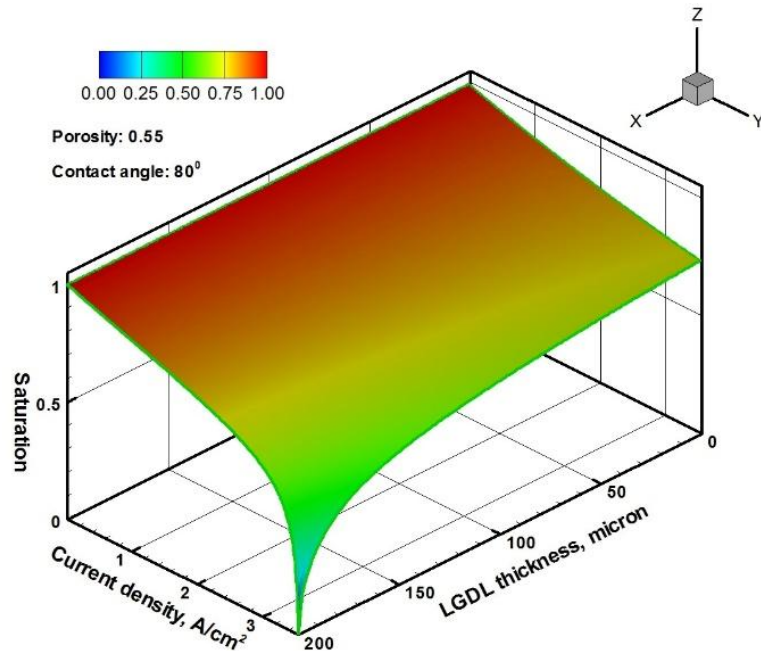

(a)

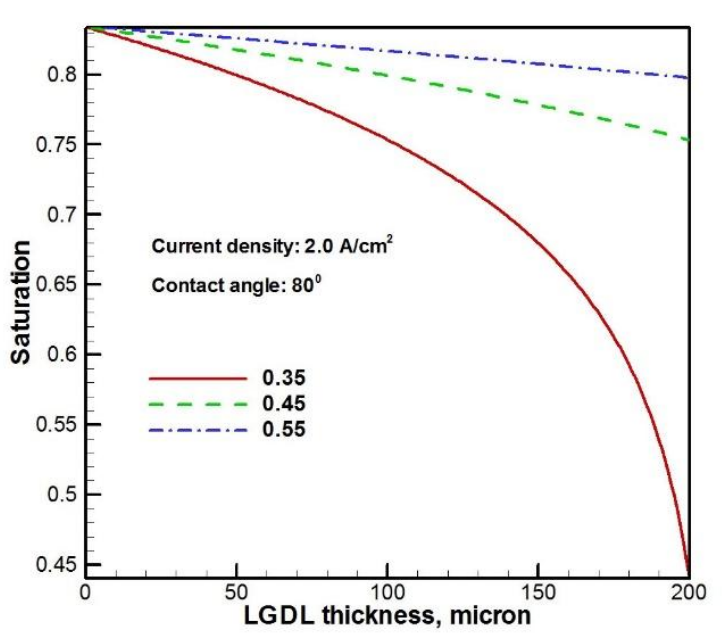

(b)

Figure 5 


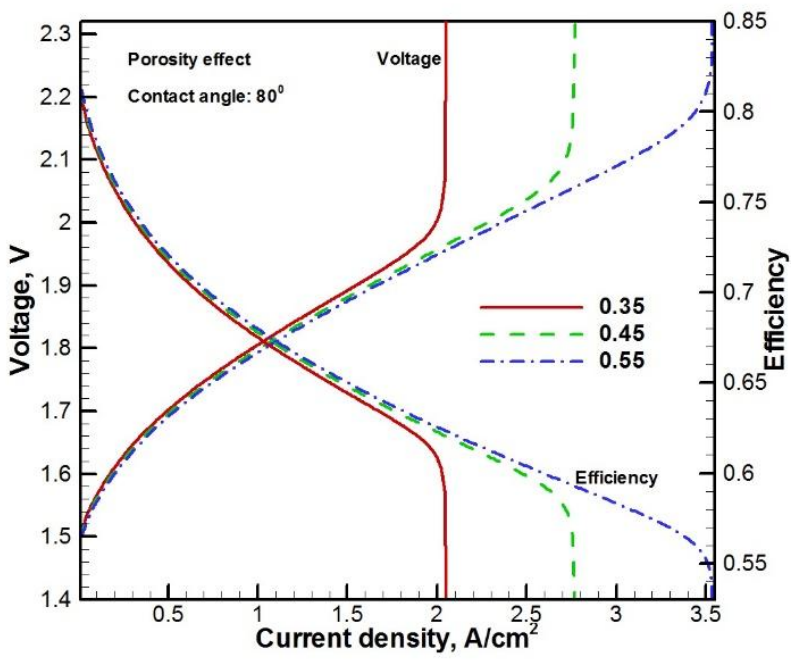

Figure 6 


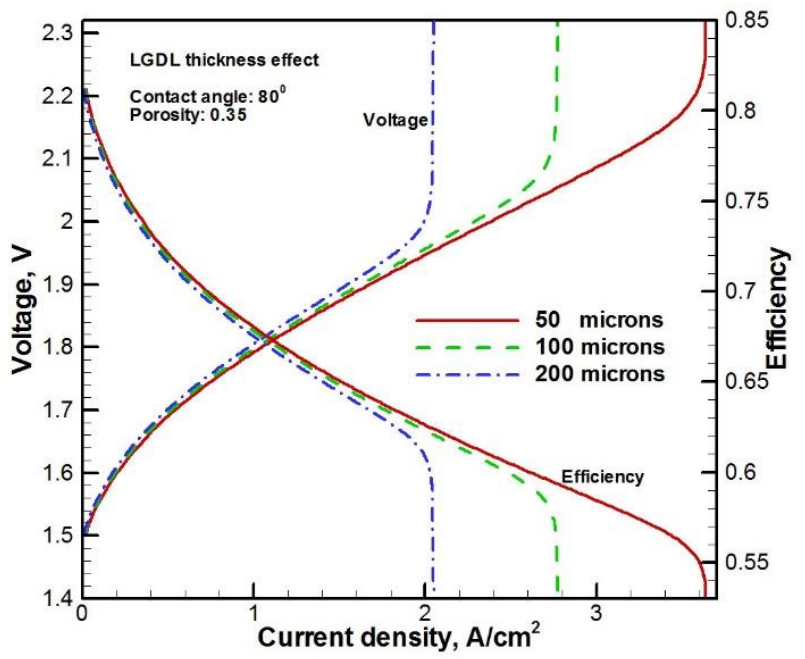

Figure 7 


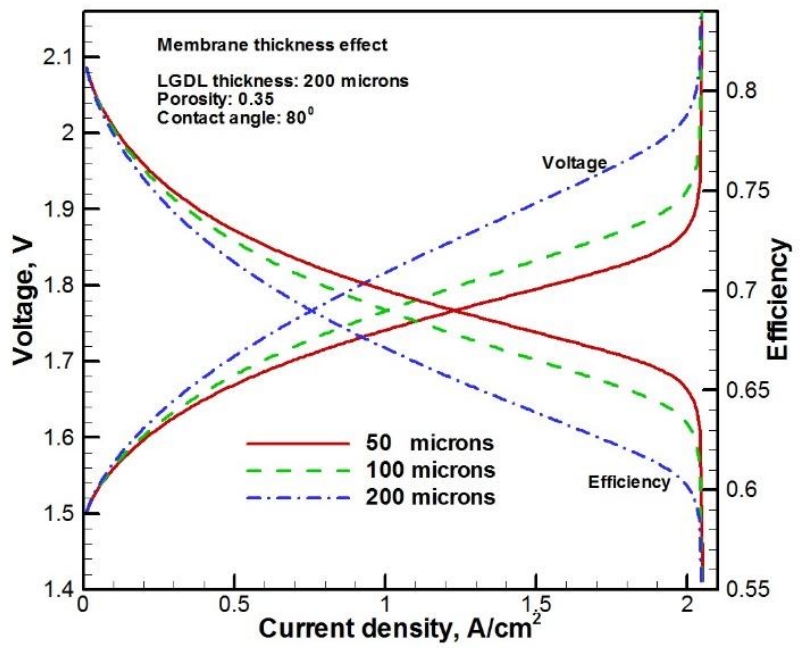

Figure 8 